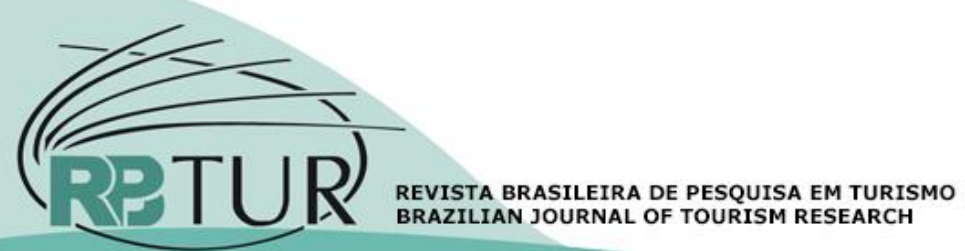

\title{
Artigos
}

\section{Parcerias e concessões para o desenvolvimento do turismo nos parques brasileiros: possibilidades e limitações de um novo modelo de governança}

\author{
Partnerships and concessions for the development of tourism in \\ Brazilian parks: possibilities and limitations of a new governance model
}

\section{Parcerias y concesiones para el desarrollo del turismo en los parques brasileños: posibilidades y limitaciones de un nuevo modelo de gobernanza}

Camila Gonçalves de Oliveira Rodrigues; Fernando Luiz Abrucio²

${ }^{1}$ Universidade Federal Rural do Rio de Janeiro (UFRRJ), Rio de Janeiro, Rio de Janeiro, Brasil

2Fundação Getúlio Vargas (FGV), São Paulo, São Paulo, Brasil

Palavras-chave:

Turismo;

Concessões;

Regulação;

Áreas protegidas.

Keywords:

Tourism;

Concessions;

Regulation;

Protected areas.
Resumo

A participação privada na prestação de serviços de apoio ao turismo em parques é estimulada por órgãos ambientais de diversos países como uma estratégia para aprimorar a implementação dessas áreas. 0 objetivo deste artigo é analisar os principais aspectos que orientam o planejamento, a implementação e o monitoramento das parcerias entre as esferas pública e privada, com ênfase nas concessões e nas iniciativas no âmbito federal e nos estados de Minas Gerais (MG), Rio de Janeiro (RJ) e São Paulo (SP). A partir de análise de referencial teórico-conceitual sobre valores públicos nas parcerias e uma abordagem qualitativa junto aos gestores, foram identificados alguns aspectos analíticos para subsidiar a compreensão sobre esse modelo de gestão. A possibilidade de avanço na gestão dos parques por meio de parcerias depende de características da governança estabelecida por meio de três elementos principais: a transparência, de modo a aumentar a capacidade de os reguladores e a sociedade controlarem o desempenho; a criação de uma comunicação eficaz, que estimule a confiança entre os setores envolvidos; e a participação social, que fortalece a accountability e aumenta a legitimidade do processo.

Abstract

Private sector participation in the provision of tourism support services in parks is encouraged by environmental agencies in several countries as a strategy to improve the implementation of these areas. The objective of this article is to analyze the main aspects that guide the planning, implementation, and monitoring of partnerships between public and private sectors, with emphasis on concessions and initiatives at the federal level and in the states of Minas Gerais (MG), Rio de Janeiro (RJ), and São Paulo (SP). Based on the analysis of a theoretical/conceptual framework on public values in partnerships and a qualitative approach with the managers, some analytical aspects were identified to support the understanding of this management model. Partnerships have the potential to favor park 
Palavras clave:

Turismo;

Concesiones;

Regulación;

Áreas protegidas

Revisado por pares.

Recebido em: 20/11/2018.

Aprovado em: 09/04/2019.

management in terms of innovation, human resources, efficiency, and others. But this pos sibility of advancement depends on the characteristics of the governance established, through three main elements: transparency, in order to increase the capacity of regulators and society to control performance; the creation of effective communication, which builds trust among the sectors involved; and social participation, which strengthens accountability and increases the legitimacy of the process.

Resumen

La participación privada en la prestación de servicios de apoyo al turismo en parques es estimulada por organismos ambientales de diversos países como una estrategia para mejorar la implementación de esas áreas. El objetivo de este artículo es analizar los principales aspectos que orientan la planificación, la implementación y el monitoreo de las alianzas entre las esferas pública y privada, con énfasis en las concesiones y en las iniciativas en el ámbito federal y en los estados de Minas Gerais (MG), Río de Janeiro Y en el caso de las mujeres. A partir de análisis de referencial teórico-conceptual sobre valores públicos en las alianzas y un abordaje cualitativo junto a los gestores, se identificaron algunos aspectos analíticos para subsidiar la comprensión sobre ese modelo de gestión. La posibilidad de avanzar en la gestión de los parques a través de asociaciones depende de las características de la gobernanza establecida a través de tres elementos principales: la transparencia, para aumentar la capacidad de los reguladores y la sociedad para controlar el desempeño; la creación de una comunicación eficaz, que estimule la confianza entre los sectores implicados; y la participación social, que fortalece la accountability y aumenta la legitimidad del proceso.

Como citar: Rodrigues, C.G.O.; Abrucio, F.L. (2019). Parcerias e concessões para o desenvolvimento do turismo nos parques brasileiros: possibilidades e limitações de um novo modelo de governança. Revista Brasileira de Pesquisa em Turismo, São Paulo, 13 (3), p. 105 120, set./dez. http://dx.doi.org/10.7784/rbtur.v13i3.1575

\section{INTRODUÇÃO}

A recreação e o turismo são motivações que atraem pessoas para os ambientes naturais, gerando uma nova forma de ocupação e apropriação destas áreas. Os parques nacionais, tipo de área protegida existente em várias partes do mundo (Balmford et al. 2015), abrangem territórios nos quais a qualidade ambiental, a beleza cênica, as opções de lazer e os elementos culturais constituem aspectos que atraem interesses sociais e econômicos, mas que devem ser regulados publicamente.

A participação privada na prestação de serviços de apoio ao turismo em parques tem sido estimulada por órgãos ambientais de diversos países como uma estratégia para aprimorar a implementação dessas áreas. Assim, por meio de diferentes arranjos institucionais, os órgãos públicos promovem parcerias com a iniciativa privada, com e sem fins lucrativos, buscando apoio para a consecução dos objetivos das áreas protegidas (Eagles, 2009; Wyman et al., 2011; Thompson, Massyn \& Pastorelli, 2014).

No caso brasileiro, os parques são instituídos pelo poder público como medida de proteção de ecossistemas naturais e estão sujeitos a um regime especial de proteção (Brasil, 2000). Portanto, são bens públicos cuja utilização é orientada por padrões e regulamentos que visam garantir a qualidade ambiental e a experiência do visitante nestes espaços.

Desta forma, para diversificar a oferta de serviços e atividades de apoio à visitação e captar investimentos para aprimorar o turismo nos parques, a esfera pública adota instrumentos como a concessão, permissão e autorização para uso privativo de bem público ou prestação de serviços, utilizados para viabilizar a participação privada, com fins lucrativos. Nesse processo, tem-se um desafio colocado pela necessária adoção de diferentes modelos de gestão e integração entre os campos de conhecimento da administração pública, associado à política ambiental, e do planejamento da oferta e demanda de serviços, vinculado ao setor de turismo.

Alguns estudos (Rocktaeschel, 2006; Rodrigues \& Godoy, 2013; Braga, 2013; Matheus \& Raimundo, 2017) destacam o tema das parcerias para o turismo em parques, mas a discussão sobre as estratégias de implementação e os efeitos dessas iniciativas é incipiente e, portanto, inovadora no que se refere à contribuição que pode aportar para a gestão do turismo em áreas públicas, como é o caso dos parques. 
Diante deste contexto, este artigo tem como objetivo analisar os principais aspectos que orientam o planejamento, a implementação e o monitoramento das parcerias para o desenvolvimento do turismo nos parques brasileiros, considerando a perspectiva dos gestores dos órgãos responsáveis por estas áreas no âmbito federal e nos estados de Minas Gerais (MG), Rio de Janeiro (RJ) e São Paulo (SP). Ao fazer essa discussão, o objetivo é apresentar os pressupostos desse modelo de governança, realçando suas possibilidades e limitações.

\section{REFERENCIAL TEÓRICO}

\subsection{Atividades em contato com a natureza: apontamentos teórico-conceituais sobre as parcerias para o desenvolvimento do turismo em unidades de conservação}

A dinâmica do turismo em unidades de conservação insere-se numa discussão ampla sobre as diferentes formas de apropriação e acesso aos parques e demais áreas protegidas. As atividades praticadas em contato com a natureza - tais como recreação, turismo, esporte, educação ambiental etc - podem ser contempladas no bojo do termo "uso público", que caracteriza o aproveitamento de áreas protegidas pelo público em geral, por meio da visitação, independentemente da motivação, origem do visitante ou segmento do turismo em questão (ecoturismo, turismo de aventura) (Ministério do Meio Ambiente, 2006).

Assim, na medida em que o turismo tem sido tratado no âmbito das políticas públicas de diferentes países, inclusive no Brasil, como uma importante estratégia para a conservação da natureza, surge também a necessidade de uma maior integração entre as políticas de turismo e da área ambiental (Buckley, 2012; McCool \& Spenceley, 2014; Secretariat of the Convention on Biological Diversity, 2015; Instituto Chico Mendes de Conservação da Biodiversidade, 2018). Neste sentido, os órgãos ambientais que administram as áreas protegidas, ao permitir e incentivar o acesso de visitantes para a prática do turismo em contato com a natureza, buscam também investir em infraestrutura e técnicas de manejo da visitação compatíveis com as especificidades de cada área, sobretudo no que diz respeito à preservação dos bens naturais e culturais.

É nesse contexto desafiador de planejamento e gestão do turismo em unidades de conservação que as parcerias e concessões surgem como uma das alternativas para os órgãos públicos. Todavia, o tema das parcerias suscita debates e posicionamentos divergentes sobre a maneira como o bem público dever ser gerido e utilizado. Argumentos como o de que as parcerias fazem parte de um projeto neoliberal do governo que visa transferir cada vez mais responsabilidades para a iniciativa privada ou de que os processos de concessão podem gerar a elitização do acesso aos bens públicos são utilizados de maneira contundente pelas vertentes críticas ao processo. Por outro lado, as parcerias e concessões são defendidas como uma forma de ampliar a participação privada, considerando a experiência e a capacidade de investimento do setor, possibilitando a ampliação de infraestrutura nos parques.

Os posicionamentos expressam diferentes visões sobre a gestão da coisa pública. Neste artigo vamos explorar alguns aspectos desse debate, contudo, o recorte analítico escolhido aqui prioriza a análise da visão dos gestores públicos envolvidos no processo, procurando mostrar a perspectiva de atores-chave dessa nova forma de governança. Trata-se de um ângulo importante e diferente na literatura sobre o tema, que pode destacar, no contexto da implementação, variáveis críticas desse instrumento de gestão. Claro que essa visão não esgota a compreensão do fenômeno, mas pode trazer subsídios para entendê-lo melhor.

As parcerias podem ser reguladas por um amplo leque de arranjos institucionais. A prestação de serviços de apoio ao turismo em parques, ainda que não esteja expressa no bojo do conceito de serviço público, tem utilizado, subsidiariamente, a legislação para a prestação de serviços públicos como a Lei no 8.987, de 13 de fevereiro de 1995 (Lei das Concessões e Permissões), que orienta a concessão "comum", e a Lei 11.079, de 30 de dezembro de 2004 (Lei das Parcerias Público-Privadas - PPP), que institui duas modalidades de concessão, a patrocinada e a administrativa (Rodrigues \& Godoy, 2013).

Além destas normas, a Lei 13.668, de 28 de maio de 2018, dispõe sobre a concessão de serviços, áreas ou instalações de unidades de conservação federais para a exploração de atividades de visitação em contato com a natureza, mediante procedimento licitatório. 0 instrumento também dispensa o chamamento público 
para celebração de parcerias, nos termos da Lei no 13.019, de 31 de julho de 2014 (Marco Regulatório das Organizações da Sociedade Civil), com associações representativas das populações tradicionais para a exploração de atividades relacionadas ao uso público. Com a publicação dessa lei, o Instituto Chico Mendes de Conservação da Biodiversidade (ICMBio) pode desenvolver iniciativas que promovam o protagonismo dos empreendimentos locais na prestação de serviços de apoio ao turismo. Esses tipos de parceria estão sendo estudadas também no âmbito do projeto "Parcerias Ambientais Público-Privadas - PAPP", realizado em parceria como Instituto Brasileiro de Administração Municipal (IBAM) e com a cooperação do Banco Interamericano de Desenvolvimento (BID) e da Caixa Econômica Federal.

Neste artigo, a concessão para instituições privadas com fins lucrativos será enfatizada devido à ampliação de iniciativas desse modelo nos parques. 0 Quadro 1 apresenta um resumo dos principais instrumentos que podem ser utilizados na gestão em unidades de conservação.

Quadro 1 - Arranjos institucionais no âmbito da gestão do turismo em unidades de conservação no Brasil

\begin{tabular}{|l|l|}
\hline Instituições privadas com fins lucrativos & Instituições privadas sem fins lucrativos \\
\hline Concessão & Acordo de cooperação, termo de fomento e termo de colaboração \\
Permissão & com organizações da sociedade civil \\
Autorização & Termo de parceria com organização social de interesse público \\
\hline
\end{tabular}

Fonte: Os autores (2018)

As características de cada modalidade de ajuste entre a esfera pública e privada com fins lucrativos envolvem questões como envergadura econômica do projeto; tipo de parceiro (pessoa física, pessoa jurídica); tipo de documento de formalização (ato administrativo, contrato, acordo de cooperação, termo de fomento); tempo de duração do contrato. Assim, no caso das concessões, por exemplo, são firmados contratos que envolvem investimentos de médio e grande porte, e de longa duração. Já as autorizações são atos administrativos, de caráter precário e curta duração, que visam regulamentar a prestação de serviços de pequeno porte como a condução de visitantes ou aluguel de barco (Botelho \& Rodrigues, 2016).

Além dos aspectos da gestão da unidade de conservação e do turismo, o processo que envolve o estabelecimento de parcerias sugere a abordagem de temas relevantes no âmbito da administração pública, uma vez que o lócus de implementação dessas parcerias é um bem público de uso especial, criado para a proteção do patrimônio ambiental e cultural. É nesse contexto que emerge também o debate sobre a governança dos bens naturais e culturais que é em grande medida influenciada pelos benefícios recebidos (e percebidos) por diferentes setores da sociedade (Eagles, 2009).

A partir de uma pesquisa sobre as concessões em parque nacionais da Nova Zelândia, Dinica (2017) salienta que este modelo de parceria faz parte de um conjunto de ferramentas para a implementação de arranjos de governança mais amplos, os quais exercem influência na priorização dos objetivos das áreas protegidas. A autora salienta que, incentivados pelas políticas neoliberais a partir de 2009, diversos contratos de concessão foram firmados, mas os ganhos de conservação ambiental e de infraestrutura acordados no processo são questionáveis, gerando preocupações no sentido da insustentabilidade do turismo nas áreas protegidas.

Nesse contexto, destacam-se os elementos da teoria da governança, segundo a qual as questões coletivas são definidas hoje por meio de mecanismos de articulação e interação entre o governo, a sociedade e o setor privado, desenvolvidos a partir de certos modelos regulatórios que buscam, ao mesmo tempo, melhorar o desempenho e a democratização das políticas públicas (Torfing, Peters, Pierre \& Sorensen, 2012). 0 conceito de público é reformulado, indo além do estatal, mas tendo que responder a determinados valores públicos.

A questão dos valores públicos é, desse modo, um elemento central da teoria da governança. Seguindo essa linha e buscando elucidar as diferentes funções entre as esferas pública e privada na gestão das parcerias, Reynaers (2013) desenvolveu uma pesquisa sobre os valores públicos, tais como a responsabilização (accountability), transparência e qualidade, que devem ser abordados nos processos de concessão e parceria com o setor privado. Embora a autora tenha focado seus estudos no setor de infraestrutura (estrada, saneamento, transporte), os apontamentos realizados podem aportar reflexões para o contexto das parcerias para o turismo em áreas protegidas. A autora salienta que as parcerias público-privadas são 
frequentemente analisadas e elogiadas em termos de eficiência, mas o impacto dessas iniciativas nos valores públicos é muitas vezes negligenciado. Ressalta que os valores públicos podem ser ameaçados, salvaguardados ou mesmo fortalecidos, dependendo da fase do projeto e da forma como a gestão pública monitora e divulga os resultados das parcerias (Reynaers, 2013; Reynaers \& Grimmelikhuijsen, 2015).

A responsabilização, aspecto que será tratado com maior ênfase nesse artigo, pode ser entendida como um conceito multidimensional, uma vez que é concretizada por meio de diferentes ações e instrumentos (prestação de contas para a sociedade, gestão pela lógica dos resultados, controle e participação social) com vistas a que os serviços públicos respondam a valores públicos, quaisquer que sejam os provedores (estatais, privados ou organizações da sociedade civil).

À luz desse debate sobre os valores públicos nas parcerias, a gestão do turismo em unidades de conservação tende a ser permeada por questões como a responsabilidade dos diferentes sujeitos frente à utilização do patrimônio natural e cultural; o monitoramento dos impactos das concessões e parcerias; o acesso e a diversificação das oportunidades recreativas; a mediação entre interesses público e privado na gestão destas áreas, entre outas questões que dizem respeito à gestão de bens públicos.

\section{PROCEDIMENTOS METODOLÓGICOS}

A partir de análise de referencial teórico-conceitual sobre valores públicos no âmbito das parcerias entre as esferas pública e privada para a prestação de serviços para a sociedade e com base em uma abordagem qualitativa junto aos gestores públicos que atuam na política de áreas protegidas, foram identificados alguns aspectos analíticos para subsidiar a compreensão sobre as parcerias para desenvolvimento do turismo em parques.

Com o objetivo de identificar os avanços e os desafios na agenda de parcerias e concessões nos últimos cinco anos, foram realizadas entrevistas com interlocutores dos órgãos ambientais responsáveis pela gestão das áreas protegidas na esfera federal e nos estados do Rio de Janeiro, São Paulo e Minas Gerais.

As entrevistas foram realizadas entre outubro de 2017 e março de 2018. Foram registradas com um gravador e posteriormente transcritas com a autorização dos interlocutores, por meio de um termo de consentimento livre e esclarecido.

Foram entrevistados dezesseis profissionais que atuam nas instituições responsáveis pela administração das áreas protegidas no âmbito federal (8 - ICMBio) e nos estados de São Paulo (3 - governo do estado e da Fundação Florestal), Rio de Janeiro ( 3 - Instituo Estadual do Ambiente) e Minas Gerais (2 - governo do estado e Instituto Estadual de Florestas). A escolha desses estados se deve ao fato de apresentarem iniciativas de parcerias e concessões nos últimos cinco anos (2014-2018), inspiradas em processos similares.

Os profissionais não serão identificados e optou-se por uma classificação numérica sequencial de 1 a 16, que consiste no número de interlocutores que participaram da pesquisa.

A seleção dos entrevistados foi orientada pela identificação de interlocutores-chave que atuam e exercem influência direta nas políticas de visitação, com foco nos processos de concessão e demais parcerias para a prestação de serviços. Optou-se por entrevistar o quadro de profissionais dos escritórios centrais das instituições responsáveis pelas áreas protegidas. A seleção dos entrevistados na pesquisa é um ponto primordial na investigação pois interfere sobremaneira na qualidade de informações e, consequentemente, na compreensão sobre o problema em questão (Duarte, 2002). Neste sentido, cumpre salientar que o artigo apresenta uma discussão a partir do ponto de vista de parte dos gestores que atuam nas parcerias e concessões, captando um ângulo importante da questão, dado o seu lugar privilegiado na implementação do modelo, mas que não esgota o assunto. Para uma análise mais abrangente do tema, outras pesquisas poderiam abordar, por exemplo, a opinião dos visitantes e da comunidade local.

As entrevistas foram realizadas com o apoio de um protocolo de entrevista, com um roteiro de questões semiestruturado, elaboradas a partir de uma reflexão sobre os valores públicos e as diferentes fases de uma parceria. 
A análise das entrevistas foi realizada a partir de um primeiro filtro de leitura para uma "codificação" de padrões e fragmentos que permitiram a categorização dos temas de investigação (Duarte, 2002), considerando os seguintes tópicos:

- $\quad$ Significado das parcerias e de responsabilização;

- $\quad$ Planejamento das parcerias e concessões;

- Monitoramento das parcerias e desafios da agenda para os próximos anos.

A organização da análise em tópicos facilita a abordagem dos assuntos, mas não limita a interpretação em "caixas" separadas, pois os assuntos se correlacionam e se influenciam, reforçando a complexidade do tema.

Os resultados das entrevistas com os gestores do órgão federal e dos estaduais serão apresentados conjuntamente e, quando necessário, serão realizadas ressalvas e apontamentos específicos para cada caso.

\section{RESULTADOS E DISCUSSÃO}

\subsection{Panorama da prestação de serviços de apoio ao turismo nos parques nacionais e nos estados de Minas Gerais, Rio de Janeiro e São Paulo.}

As unidades de conservação (UC) são um tipo especial de área protegida, criadas pelo poder público, sob regime especial de administração ao qual se aplicam garantias adequadas de proteção. Dentre as categorias de manejo de UC existentes, este artigo aborda especificamente os parques, que apresentam como fundamentos de sua criação a preservação de ecossistemas naturais de grande relevância ecológica e beleza cênica, sendo incentivadas atividades de educação ambiental, recreação e turismo em contato com a natureza (Brasil, 2000).

O Instituto Chico Mendes de Conservação da Biodiversidade (ICMBio) é responsável pela gestão de 324 unidades de conservação, sendo que 74 parques nacionais, dos quais 4 apresentam contratos de concessão em estágio avançado, são eles: Parque Nacional do Iguaçu (PR), Parque Nacional da Tijuca (RJ), Parque Nacional Marinho de Fernando de Noronha (PE) e Parque Nacional da Serra dos Órgãos (RJ). Além desses contratos, alguns parques apresentam mais de 250 autorizações para a prestação de serviços como condução de visitantes, atividades com embarcação, entre outras atividades.

No planejamento da instituição para o período de 2018-2020 foi priorizada a efetivação do processo de concessão de serviços em sete parques. Entre o final de 2018 e início de 2019 foram assinados três contratos de concessão nos Parques Nacionais do Pau Brasil (BA), da Chapada dos Veadeiros (GO) e do Itatiaia (RJ/MG).

Em Minas Gerais, o Instituto Estadual de Florestas é responsável pela gestão de 79 unidades de conservação, sendo que 36 parques estaduais. Em 2014, o governo do estado iniciou uma série de estudos, em parceria com o Instituto Semeia ${ }^{1}$, para subsidiar o processo de implementação de uma Parceria PúblicoPrivada $(\mathrm{PPP})^{2}$, por meio de uma concessão administrativa para apoiar a gestão de três unidades de conservação, conhecido como "PPP da Rota Lund". Contudo, embora o processo tenha chegado até a seleção da empresa vencedora na licitação, o contrato de parceria não foi assinado pelo governo do estado. Em 2017, a partir de um novo entendimento do estado, o IEF está reavaliando a modelagem para a gestão das unidades da Rota Lund, que inclui o Parque Estadual do Sumidouro, além de estar conduzindo estudos para subsidiar a prestação de serviços no Parque Estadual do Itacolomi.

\footnotetext{
1 Instituição que atua em parceria com os governos federal, estadual e municipal com o objetivo de apoiar projetos que busquem novos modelos de gestão de parques naturais e urbanos.

2 Lei 11.079, de 30 de dezembro de 2004, que institui normas gerais para licitação e contratação de parceria público-privada no âmbito da administração pública.
} 
No estado do Rio de Janeiro, também motivado por uma parceria com o Semeia, o Instituto Estadual de Meio Ambiente (INEA) promoveu o desenvolvimento de estudos para a implementação de uma PPP no Parque Estadual de Ilha Grande. Contudo, o projeto não foi finalizado em virtude de questões de continuidade do processo e da gestão no INEA, mas também pela reação contrária de moradores e de diversos segmentos da Ilha Grande que questionaram o modelo apresentado pelo estado.

O INEA é responsável pela gestão de 29 unidades de conservação, sendo que 11 parques estaduais. Até outubro de 2018 nenhum parque apresentava contrato de concessão. Contudo, de acordo com informações fornecidas pelo órgão, estão em andamento os processos de concessão de serviços para lanchonete e loja de souvenires nos parques estaduais da Pedra Branca e de Cunhambebe.

Também foi informado pelo INEA que para os serviços e atividades de menor porte, como a venda de alimentos e de artesanato, prestados em áreas privadas que ainda não foram regularizadas, o procedimento tem sido o registro desses prestadores e a orientação para o ordenamento das atividades, considerando o manejo dos impactos ambientais e a qualidade dos serviços prestados.

No estado de São Paulo, a Fundação Florestal (FF) é responsável por 110 unidades de conservação, sendo que 34 parques estaduais. Em alguns parques, como Campos do Jordão, Intervales, Serra do Mar, serviços como lanchonete, camping, loja de souvenires são disponibilizados via permissão para a iniciativa privada. E, em 2016, o governo do estado de São Paulo editou a Lei Estadual 16.260, de 29 de junho de 2016, que autoriza a concessão para exploração de serviços ou uso para o desenvolvimento de atividades inerentes ao ecoturismo e à exploração comercial de madeira ou subprodutos florestais. Com base nessa lei, a FF está coordenando o processo de concessão de serviços em alguns parques, como o de Campos de Jordão e da Cantareira.

\subsection{0 sentido das parcerias e o significado de responsabilização}

Um dos primeiros questionamentos consistiu em apontar o sentido das parcerias e o significado de responsabilização nesse processo. As parcerias foram abordadas no sentido amplo, entendidas como os diferentes ajustes entre o Estado e a iniciativa privada, com ou sem fins lucrativos. Contudo, alguns interlocutores frisaram a diferença entre uma parceria entendida também como um "negócio" para a iniciativa privada com fins lucrativos, e a parceria como uma forma de atuação do terceiro setor para atingir objetivos sociais, ambientais e educativos.

Dois argumentos principais foram ressaltados para explicar e justificar o sentido das parcerias. 0 primeiro, citado de maneira bastante contundente, relaciona-se à capacidade de gestão do Estado, sob o ponto de vista do aporte de recursos financeiros e humanos para gerir, com eficiência, as unidades de conservação.

O segundo ponto salientado por alguns interlocutores diz respeito ao impacto das parcerias no alcance dos objetivos institucionais do Estado, que no caso dos órgãos ambientais que administram as UC, está associado à conservação da natureza, em bases sustentáveis e participativas, conforme expresso nas diretrizes da Lei 9.985, de 18 de julho de 2000, que instituiu o Sistema Nacional de Unidades de Conservação da Natureza (Brasil, 2000).

No que diz respeito à capacidade de gestão do Estado, um dos interlocutores salientou que a parceria é uma questão de "sobrevivência" para as unidades de conservação.

“É uma questão de sobrevivência. A fragilidade dos governos é crescente. 0 parceiro não vai investir no parque porque ele acha que eu sou bacana, ele vai investir porque tem interesse, porque enxerga um negócio. E eu vou fazer a parceria porque eu quero que ele cubra um rombo. A participação privada exige uma ruptura com um modelo de gestão fechado, com base apenas na estrutura governamental. Mas como qualquer processo de ruptura, ele gera receios e dúvidas..." (interlocutor 14, INEA, 2017).

0 "rombo" associado à deficiência de recursos financeiros e humanos na área ambiental também foi ressaltado por outro interlocutor que entende que a parceria é uma condição essencial para que as instituições ambientais possam cumprir a missão institucional do Estado, caso contrário não seria possível realizar as diversas funções com qualidade. 
Entretanto, uma das funções das unidades de conservação é promover o acesso da sociedade para fins de recreação, educação e turismo em contato com a natureza. Neste sentido, na medida em que o Estado cria uma unidade de conservação, que é um instrumento da política pública ambiental, as condições básicas de gestão e manejo da área deveriam ser garantidas. Mas a crescente diminuição do orçamento na área ambiental tende a gerar uma relação de dependência de investimentos privados e não uma perspectiva de parceria com estrutura forte e qualificada por parte do Estado.

Também foi destacada a questão da "expertise" da iniciativa privada, sobretudo no que diz respeito à prestação de serviços de apoio ao turismo como hospedagem, alimentação, transporte. Desta forma, o Estado busca no parceiro privado o conhecimento da dinâmica do mercado turístico para ofertar de serviços com qualidade e eficiência. Nesse sentido, um dos interlocutores ressalta que:

\footnotetext{
“A gente quer fazer parcerias por alguns motivos. Eu acho que um motivo importante é que a gente não é especialista em tudo. A gente vai ter muito mais qualidade do serviço e melhor arrecadação se a gente colocar um especialista no assunto da oferta de turismo, até porque o serviço público é muito moroso, a gente demora para contratar. Outro ponto é que a gente traz o privado para trabalhar com a gente, que é importante pra movimentar a economia, e a gente pode trabalhar com pequenos proprietários, a gente pode trabalhar com comunidades tradicionais, então a gente acaba gerando uma oportunidade de desenvolvimento para a região também" (interlocutor 4, ICMBio, 2017).
}

Além da questão das competências de cada setor no que diz respeito aos diferentes serviços prestados, de conservação e de apoio ao turismo, o depoimento acima salienta a questão do impacto da participação privada na economia local, associado também ao potencial de arranjos institucionais que envolvam pequenos e médios empreendedores.

O tema da participação efetiva das populações locais no desenvolvimento do turismo, conforme apontam Botelho e Rodrigues (2016), ainda é incipiente no âmbito dos programas e iniciativas das instituições ambientais, que têm priorizado a agenda de concessões com investimentos de grande porte. Assim, não se trata apenas de evidenciar a geração de emprego e renda por meio das concessões, mas principalmente de adotar um modelo que problematize a qualidade dos empregos gerados, o envolvimento da população na tomada de decisão sobre um processo de concessão e o impacto socioeconômico das concessões no contexto local.

Quanto ao sentido das parcerias vinculado aos objetivos institucionais, alguns interlocutores entendem que as parcerias devem tomar como pressuposto a função precípua dos órgãos ambientais de conservação da natureza, funcionando como um meio para que as UC alcancem seus objetivos, dentre os quais o de promover o uso público em contato com a natureza. Neste sentido, um interlocutor reforça que: "a parceria tem que estar alinhada com os objetivos institucionais do Estado e com os princípios gerais da administração pública". (interlocutor 8, ICMBio, 2017). E outro interlocutor completa que:

\footnotetext{
"A área continua sendo pública, a gestão passa a ser privada. Não é o meu sonho de consumo, mas funciona, principalmente em países que não têm recursos. Se o Estado fizer a sua parte, que é minimamente do monitoramento, a concessão é uma forma, é um meio. Na minha cabeça a responsabilidade última é sempre do Estado, então você tem que ser capaz de acompanhar a execução. 0 que difere a parceria de uma privatização, né, na privatização você vende e esquece, numa concessão você terceiriza, mas o responsável em última análise ainda é o Estado (interlocutor 3, ICMBio, 2017)".
}

As competências e atribuições da esfera pública na gestão do patrimônio natural e cultural são, neste sentido, a base de sustentação que o Estado deve se pautar contra a captura da "coisa pública" e na defesa do que Bresser-Pereira denomina como "direitos republicanos", associados ao acesso dos cidadãos aos bens públicos (Bresser-Pereira, 1998, p. 162).

Ponto importante salientado por um dos interlocutores do ICMBio foi a necessidade de adotar uma visão mais ampla das parcerias. Essa questão é chave para pensar a governança para além da relação com o setor privado com fins lucrativos. Para o entrevistado, a concessão funciona como uma parceria "mais de negócio, como um contrato comercial", mas acredita em uma parceria menos comercial, com as organizações da sociedade civil. Citou o exemplo da parceria firmada, por meio de acordo de cooperação, com o Instituto Ekos, organização da sociedade civil sem fins lucrativos, para apoiar a execução de atividades do plano de uso público no Parque Nacional Cavernas do Peruaçu, localizado no estado de Minas Gerais. 
Outro aspecto frisado por alguns interlocutores é a parceria realizada com o objetivo de ampliar a participação social na gestão das UC. Isso significa, como ressaltou um dos interlocutores, colocar em prática uma das diretrizes do SNUC associada à cooperação de organizações não-governamentais, populações locais e iniciativa privada para o desenvolvimento de atividades de lazer e turismo em contato com a natureza. Essa questão resgata o que foi colocado no início do artigo: a governança propõe a busca simultânea do melhor desempenho e da democratização das políticas públicas (Torfing, Peters, Pierre \& Sorensen, 2012).

Com relação ao entendimento sobre o conceito e as formas de implementação da responsabilização no âmbito das parcerias, ainda que alguns interlocutores tenham solicitado uma explicação mais precisa do que o termo significava, na medida em que colocavam suas opiniões, temas como a prestação de contas para a sociedade e a forma como o Estado monitora e divulga os resultados das parcerias foram levantados como chaves de interpretação sobre a responsabilização. Tal situação indica uma abordagem ampla, reforçando a importância de se pensar o caráter multidimensional da responsabilização (CLAD, 2006; Reynaers, 2013)

No estado de Minas Gerais, por exemplo, o depoimento de um dos interlocutores reforça as diferentes dimensões da responsabilização no contrato de uma concessão comum ou de uma parceria público-privada:

\footnotetext{
“Aqui a gente tem bastante preocupação com a questão de responsabilização. A gente tenta trabalhar desde o início, por exemplo, com Tribunal de Contas, com a Controladoria Geral do Estado. E também pensamos na responsabilização além dos órgãos de controle, buscando aplicar internamente também. Por exemplo, pensando na continuidade das equipes que participaram da modelagem de uma parceria. É importante garantir o mínimo de manutenção dessas pessoas para ter retenção do conhecimento e legitimidade no controle e monitoramento dos parceiros privados " (interlocutor 16, governo do estado de Minas Gerais, 2018).
}

O termo responsabilização foi abordado também como um processo de distribuição de responsabilidades entre os entes público e privado, nas palavras de um profissional do estado de São Paulo: "responsabilização na minha cabeça é a definição clara de quais atores são responsáveis por determinadas atividades, determinados riscos, determinadas atribuições que foram deixadas claras no contrato, na licitação" (interlocutor 11, governo do estado de São Paulo, 2017).

No que diz respeito ao acompanhamento do contrato, interlocutores do ICMBio e do estado de Minas Gerais, frisaram a importância do conselho gestor da unidade de conservação funcionar como o lócus para a divulgação e discussão sobre os resultados das concessões e parcerias.

\begin{abstract}
"A gente já tem um histórico de fracasso de projetos que foram mal entendidos pela população local. $E$ a gente tem o conselho da unidade. Eu acho que a grande jogada nossa para a participação social no acompanhamento do contrato é via conselho. 0 conselho é o lugar onde temos que apresentar relatórios periódicos e acompanhar como que está sendo feito. Por exemplo divulgar também na web quanto visitantes estamos recebendo, o que estamos arrecadando e o que a concessionária arrecadou. Para um cidadão que quer saber como que funciona a concessão lá no lguaçu ou na Serra dos Órgãos, quantos empregos diretos e indiretos foram gerados com a concessão". (interlocutor 1 , ICMBio, 2017)
\end{abstract}

Neste sentido, a responsabilização por meio da prestação de contas e da participação social encontra no conselho gestor um ambiente promissor para a sua efetivação. Em Minas Gerais, um dos interlocutores também enfatizou que parte da prestação de contas para a sociedade pode ser encaminhada via conselho gestor da unidade. As reuniões e atividades do conselho funcionam como canais de geração de conhecimento e divulgação de informações e, ao mesmo tempo, instância de tomada de decisão e definição de responsabilidades compartilhadas. É neste sentido que a responsabilização via controle social tende a gerar uma maior democratização no processo de implementação de uma política pública (CLAD, 2006; GRAU, 2006).

No estado de São Paulo, os interlocutores ressaltaram a complexidade associada ao processo de concessão, considerando os setores interessados na proposta e os moradores locais que serão afetados direta e indiretamente na proposta. Além das etapas de comunicação e consulta externas, internamente a Fundação Florestal deve cumprir um fluxo de análise e aprovação em algumas instâncias da instituição. Dessa forma, conforme salienta um interlocutor da instituição em relação ao longo período investido no processo de elaboração do edital de concessão até o seu lançamento: "se a gente perde um mês, não é que a gente tá 
perdendo o mês, a gente tá ganhando o mês lá na frente porque a gente tá consolidando um processo que terá menos questionamentos e entraves no futuro" (interlocutor 10, Fundação Florestal, 2017).

Mas, ainda que o estado tenha adotado diferentes formas de promover a participação, posicionamentos contrários à concessão, motivados também pelo histórico de conflitos, dentre os quais a sobreposição entre unidades de conservação e territórios onde vivem populações tradicionais, são liderados por movimentos sociais e organizações da sociedade civil que questionam a legitimidade do processo (Braga de Souza, 2017).

\subsection{Planejamento das parcerias e concessões para a prestação de serviços de apoio ao turismo}

O planejamento de uma parceria ou de uma concessão caracteriza-se por um processo que envolve diferentes etapas, tais como a observação da base legal e dos instrumentos que orientam as parcerias na administração pública; a definição e a modelagem do arranjo institucional mais adequado para cada contexto e unidade de conservação; a realização de estudos de viabilidade econômica; a adoção de mecanismos de participação social na definição dos modelos (Rodrigues \& Godoy, 2013). Estes aspectos foram abordados pelos interlocutores durante as entrevistas e expressam as ações que os órgãos ambientais vêm tomando no sentido de consolidação das parcerias.

Um tema que foi levantado com frequência pelos interlocutores na esfera federal e também nos estados diz respeito aos estudos e investimentos realizados para adotar a parceria público-privada (PPP), nos termos da Lei 11.079 , de 30 de dezembro de 2004, na gestão e prestação de serviços de apoio do turismo em unidades de conservação. Com o apoio do Instituto Semeia, sobretudo entre os anos de 2013 e 2016, os estados de Minas Gerais e Rio de Janeiro, desenvolveram diversas iniciativas no sentido de viabilizar um contrato de concessão, nos moldes da PPP. Contudo, até outubro de 2018 nenhuma parceria utilizando esse modelo foi firmada em unidade de conservação.

No estado do Rio de Janeiro, o INEA contratou estudos para subsidiar o desenvolvimento de uma PPP no Parque Estadual da llha Grande. Esse processo desencadeou uma série de questionamentos por parte das organizações e comunidade local que, somada aos desafios do estado para avançar com uma parceria desse porte, resultou na suspensão do processo. Interlocutores do INEA relataram a experiência que o órgão teve como o processo da PPP no Parque Estadual da llha Grande, enfatizando alguns equívocos do processo:

\footnotetext{
"O principal seria trabalhar todos os aspectos do que seria necessário para aquela região e depois indicar o modelo. Outro ponto é a comunicação. A sociedade ainda vê com muito preconceito a parceria do Estado com o ente privado." (interlocutor 13, INEA, 2017).
}

O depoimento acima indica um aprendizado no processo de interação com a comunidade local. Assim, o investimento realizado nos estudos para a PPP parece ter resultado num ciclo de amadurecimento para os profissionais envolvidos, tanto da esfera pública quanto da esfera privada.

Em Minas Gerais, o projeto da "PPP da Rota Lund", realizado também com o apoio do Semeia, não foi concretizado. Existe um entendimento, por parte dos entrevistados, de que a questão política, expressa no posicionamento contrário ao projeto em virtude da mudança de governo, foi um dos principais entraves para a continuidade do processo. Além disso, a questão do aporte de recursos públicos para o projeto também ficou comprometida diante do alto custo das contraprestações que o estado deveria alocar. Portanto, em fevereiro de 2018, o gestor do governo do estado informou que eles estavam retomando o projeto, mas agora com outro foco e envergadura. No projeto da PPP estavam previstas ações de manejo e conservação, além de atividades relacionadas à prestação de serviços de apoio ao turismo.

No contexto das parcerias para apoiar a gestão das UC é importante refletir sobre o papel do Instituto Semeia, que foi criado com o objetivo de ampliar a participação privada neste processo. Em um determinado momento, a instituição, também motivada por uma tendência de promoção das PPP em diversos setores de governo, firmou a cooperação com os governos estaduais para adoção do modelo nos parques. No entanto, como ressaltado anteriormente, os modelos importados de outros países e setores, descontextualizados do território e impostos sobre as populações, tendem a gerar conflitos e posições contrárias, que se intensificam devido ao histórico de uso e ocupação do espaço. Neste sentido, o planejamento destas parcerias passa 
principalmente por um ganho de legitimidade no contexto local e também pelo respeito às diferentes visões sobre como acessar os bens naturais e culturais, em sentido amplo.

No âmbito federal, alguns estudos também foram desenvolvidos no sentido de subsidiar a modelagem de uma PPP em parques nacionais. Um dos interlocutores do ICMBio chamou a atenção para o fato de que existiu no governo um período em que estavam sendo estimuladas a adoção da PPP em diversas políticas públicas. Assim, na visão dele, o ICMBio "embarcou" nessa possibilidade, mas nenhuma proposta foi concretizada.

\begin{abstract}
"Perdemos o "time" da PPP e agora precisamos investir num caminho próprio para as UC. Precisamos investir no entendimento dos diferentes instrumentos de delegação e parceria. E precisamos do apoio da universidade e de especialistas para construir isso. 0 fato de a gente não ter a nossa base legal e conceitual estruturada faz com que a gente fique sempre à reboque de outros setores e da intepretação diversificada dos procuradores do ICMBio" (interlocutor 5, ICMBio, 2017).
\end{abstract}

Da mesma forma, outro interlocutor do ICMBio salienta que a instituição precisa avançar numa legislação própria, adequada à função principal das áreas protegidas vinculada à conservação. Ele acredita que a instituição deve evitar modelos que gerem um problema de gerenciamento com mais risco de desvio de função de um "Parque Nacional para um Parque de Diversões", se referindo ao excesso e tipo de infraestrutura que estimula o consumo de serviços, descolado de um aproveitamento que também pode gerar sensibilização e conhecimento. Desta forma, na medida em que a visitação é planejada a partir de uma visão que prioriza a viabilidade econômica por meio da implementação de serviços, de equipamentos e de infraestrutura, alguns temas como a diversidade de oportunidades recreativas, a noção de patrimônio público e a percepção do público visitante sobre a função do espaço podem assumir diferentes contornos (Rodrigues \& Irving, 2015).

Outro tema que afeta o planejamento das parcerias e que foi bastante citado durante as entrevistas diz respeito à diversidade de arranjos entre a esfera pública e privada, com ou sem fins lucrativos. Um tema recorrente nesse debate é a participação das iniciativas protagonizadas pelos empreendimentos locais, de micro e pequeno porte.

O depoimento de um dos interlocutores do ICMBio reforça a questão da diversidade de arranjos, acompanhando diferentes contextos e dinâmicas de visitação nos parques. Na sua opinião:

\begin{abstract}
"A concessão é viável para unidades que têm visitação de massa, até porque ela depende de uma viabilidade econômica. Então não é um modelo que se adequa a todas as categorias e toda a diversidade de situações nas unidades. Então a gente trabalha muito também com as autorizações. É um processo bem interessante porque ele pode servir para cadastrar os operadores de serviço e também como normas de ordenamento" (interlocutor 7, ICMBio, 2017).
\end{abstract}

Neste sentido, as autorizações têm sido utilizadas como um instrumento relevante para formalizar, principalmente, a atuação de iniciativas lideradas por empreendedores locais. Contudo, ainda que a adoção de outros instrumentos esteja avançando, as concessões são citadas com mais frequência na agenda do governo federal (ICMBio, 2018) e também de alguns estados.

Um dos interlocutores do estado de São Paulo salienta a dedicação de seu trabalho focada principalmente nos processos de concessão:

\footnotetext{
“O processo de concessão ocupa $100 \%$ do meu tempo, por isso que é importante estruturar melhor esse núcleo de parcerias. Existe um mito que alguns gestores acreditam que a concessão vai resolver todos os problemas. E isso não é bem assim, o gestor terá que dedicar boa parte do seu tempo para a gestão adequada dos contratos". (interlocutor 9, Fundação Florestal do estado de São Paulo, 2017).
}

A gestão e o monitoramento adequados das parcerias, portanto, depende de uma estrutura condizente, em termos quantitativos e qualitativos, para conduzir o processo de forma adequada, considerando aspectos como conservação da natureza, diversidade de oportunidades e acesso, protagonismo dos empreendimentos locais, qualidade dos serviços prestados, entre outros. Assim, o processo de concessão ou parceria exige um Estado forte e capacitado, de modo que a agenda de governança vai muito além de um jogo de repasse de funções ao setor privado ou à sociedade civil. 


\title{
4.4 Monitoramento das parcerias e concessões e desafios da agenda
}

Identificar, compreender e divulgar os resultados das parcerias e concessões para a conservação e o turismo é um compromisso desafiador para as instituições envolvidas nesse processo.

Ainda que alguns avanços tenham sido alcançados no sentido de institucionalizar os procedimentos para a fiscalização do contrato, um interlocutor do ICMBio salientou o desafio do órgão para registrar, sistematizar e divulgar os resultados das concessões para a sociedade, garantindo assim uma maior transparência no processo. Na sua opinião, não se trata apenas de verificar, por meio de um check-list, se a concessionária está cumprindo todas as cláusulas contratuais. 0 monitoramento não seria conduzido como uma "camisa de força" para coibir e limitar a atuação do concessionário, mas um instrumento para fortalecer a "parceria", a co-responsabilidade, a divulgação de benefícios para a sociedade.

Neste sentido, um dos interlocutores do ICMBio ressalta as recentes iniciativas da holding Cataratas do Iguaçu, que atua nos Parques Nacionais do Iguaçu, Tijuca e Fernando de Noronha, no sentido de analisar e divulgar os impactos das concessões como parte de sua estratégica de responsabilidade socioambiental e sustentabilidade.

\begin{abstract}
“A maior parte da empresa Cataratas do Iguaçu foi adquirida por um fundo de investimento americano. Estão de olho em alguns parques porque esse negócio é bom. Mas a preocupação deles não é só o lucro, ele tem que fazer um marketing institucional também, eles têm que conquistar mercado e essa conquista passa obrigatoriamente por uma visão mais ampla de gestão da área, então o grupo Cataratas hoje tem no seu orçamento anual uma verba destinada a desenvolvimento institucional e sustentabilidade"( interlocutor 6, ICMBio, 2017)
\end{abstract}

Ressalta, desta forma, que a empresa tem equipe que atua em pesquisa e marketing, e recursos para investir em publicidade. E, por outro lado, o ICMBio, tem envidado esforços para aprimorar o monitoramento e a prestação de contas para a sociedade, mas o desafio é acentuado, conforme destaca o interlocutor do ICMBio, em virtude da carência de pessoal e estratégias de comunicação eficientes.

\begin{abstract}
"Mas a ideia de que com a chegada do concessionário a gente vai se liberar para poder cumprir outras atividades, isso não é verdade. 0 monitoramento do contrato exige demais e, dependendo do parceiro que você tem, o trabalho aumenta. Quando você tem um bom parceiro, as coisas se desenrolam de forma mais tranquila. Quando o parceiro não é tão bom, exige muito em termos de você ter que estar notificando para cumprir determinada obrigação, às vezes autuando. E esse processo nem sempre vem acompanhado de um reforço na equipe para poder dar um suporte, então realmente a gente fica sobrecarregado" (interlocutor 7, ICMBio, 2017).
\end{abstract}

Nesse contexto do monitoramento, e também pautado nas experiências de outros setores, o ICMBio está estudando a adoção de indicadores de desempenho que visam bonificar a concessionária em função do alcance de padrões de qualidade e investimento em projetos em benefício da conservação e do desenvolvimento local. A bonificação pode ser por meio da diminuição da taxa de outorga ou mesmo pela prorrogação do tempo de contrato, conforme explica o interlocutor do ICMBio.

Tais medidas incentivam a atuação das concessionárias por meio da responsabilização pela lógica dos resultados. Essa vertente da responsabilização surge na década de 1990, num contexto de transição de modelos na gestão pública como forma de incentivar a eficácia, a eficiência e a efetividade na gestão governamental. Contudo, conforme destacado no estudo desenvolvido pelo CLAD (2006), essa lógica não funcionaria apenas como uma ferramenta gerencial, mas também como uma forma de controle social. Assim, num contexto recente de ampliação de parcerias entre as esferas pública e privada, a responsabilização pela lógica dos resultados tende a repercutir nos processos de concessão, buscando realçar indicadores ambientais e socioeconômicos como medida de qualificação do desempenho da iniciativa privada.

Os indicadores de desempenho também estão sendo discutidos e incorporados nos processos de concessão no estado de São Paulo. Aspectos como conservação da natureza, qualidade dos serviços, padrões de limpeza e segurança, são categorizados por meio de indicadores de desempenho que devem ser avaliados na implementação das concessões.

“Se a empresa desempenhar $100 \%$ bem os indicadores ela só paga 5\%, se ela desempenhar apenas $90 \%$ ela vai pagar $5,8 \%$ de outorga variável, se ela desempenhar $70 \%$ bem ela vai pagar $7 \%$ de outorga 
variável. Ou seja, quanto pior o serviço desempenhado menos ela vai auferir na receita no final do ano. É interesse do Estado ficar só penalizando? Não, obviamente não. Nosso interesse é que o serviço seja bem prestado. 0 objetivo do Estado, não é auferir outorgas milionárias e muito dinheiro com esse projeto. (interlocutor 11, Fundação Florestal do estado de São Paulo, 2017).

O depoimento acima aborda um tema relevante e complexo no processo de concessões e parcerias que diz respeito à arrecadação do Estado a partir das outorgas à iniciativa privada. 0 equilíbrio econômico-financeiro do contrato é um aspecto relevante na concessão e exige a mediação e regulação do Estado no sentido de compatibilizar os investimentos realizados e os rendimentos auferidos pela iniciativa privada, mas também implementar uma política de ingressos e taxas que não onere o visitante e observe a diversidade de perfis e motivações do público (Rodrigues \& Godoy, 2013).

Neste sentido, um desafio colocado no planejamento da gestão da visitação é a diversificação de oportunidades de recreação e turismo, considerando que algumas atividades podem ser realizadas com um reduzido conjunto de infraestrutura e equipamentos oferecidos pelo parque, como é o caso de caminhada em trilhas e acesso à rios e cachoeiras.

Um interlocutor do ICMBio, ao abordar as diferentes posturas ideológicas sobre o acesso aos parques e o modelo de concessões, salienta a questão da arrecadação como um tema relevante para ser discutido.

\begin{abstract}
"Acho que a reação contrária às concessões tem em primeiro lugar uma postura claramente ideológica, aquela de o Estado ser responsável e não ver com bons olhos o setor privado. Mas por outro lado acho que vem o receio que, normalmente é real, de que quando você trabalha com contratos de concessão, você acaba criando cobranças que, digamos, restringe o acesso dos menos favorecidos economicamente. Por isso é importante pensar em programas especiais para o valor do ingresso, descontos, diversidade de atrativos" (interlocutor 2, ICMBio, 2017).
\end{abstract}

No bojo da discussão sobre a arrecadação e os preços cobrados dos visitantes surge a preocupação por parte do Estado no que diz respeito à capacitação e ao aprimoramento dos instrumentos de gestão dos contratos, sobretudo no quesito "equilíbrio econômico-financeiro". 0 campo de conhecimento relacionado à oferta e demanda de serviços requer uma abordagem de mercado que precisa ser compreendida e internalizada na elaboração dos editais e, posteriormente, dos contratos de concessão.

Por um lado, a questão da viabilidade econômica do contrato é prioritária para o andamento de uma concessão e a proposta precisa ser atraente para o investidor privado. Mas o Estado, com base em princípios e diretrizes que orientam o acesso a bens e serviços públicos, deve assegurar uma proposta de uso público que contemple diferentes perfis de visitantes e oportunidades de recreação e aprendizado em com a natureza.

Neste sentido, um dos principais desafios citados pelos interlocutores da pesquisa, tanto da esfera federal quanto da estadual, é a capacitação continuada para os gestores, buscando a preparação para uma nova frente de gestão de "negócios" associada ao uso público nos parques. Ou seja, existe um duplo sentido que a agenda de uso público pode assumir em um parque, dependendo da forma como a gestão entende e concretiza o planejamento da atividade: a viabilização de um "negócio" para a iniciativa privada e a promoção do acesso à um bem público pela sociedade. A combinação destas duas perspectivas depende da qualidade da governança em termos de transparência, comunicação com os usuários e participação da sociedade civil.

Além do tema da capacitação dos gestores, outro ponto destacado com frequência pelos entrevistados foi a melhoria na comunicação com a sociedade, buscando evidenciar as funções das unidades de conservação, o papel das instituições ambientais e a identidade institucional no âmbito das concessões. Nesta linha, um interlocutor do ICMBio ressalta que o tema uso público precisa ser efetivamente adotado na instituição como uma estratégia de conservação, e não apenas como uma "caixa registradora ou como uma obrigação que a gente tem que cumprir" (interlocutor 3, ICMBio, 2017).

Por fim, também foi destacado, sobretudo na esfera estadual, o desafio relacionado ao fluxo burocrático no processo de concessões, que ainda está sendo discutido e internalizado no âmbito dos órgãos ambientais, considerando os diferentes setores e seus respectivos pontos de vista sobre o processo (jurídico, administrativo-financeiro, técnico). 


\section{CONSIDERAÇÕES FINAIS}

Os processos de concessão e parceria em parques públicos, no Brasil ou no mundo, fazem parte de um modelo abrangente de uma nova forma de governança, em que as decisões coletivas, o provisionamento dos serviços e a accountability envolvem a participação e a readequação dos três setores (governo, empresas e organizações da sociedade) para uma atuação conjunta.

Muitos são os desafios para construir essa nova governança e há uma ampla agenda de pesquisas nesse tema (Eagles, 2009; Torfing, Peters, Pierre \& Sorensen, 2012). Evidentemente que há um leque maior de formas de gestão de parques públicos, incluindo modelos liderados por comunidades locais. Contudo, buscou-se entender o formato institucional da concessão, priorizado recentemente no Brasil, mas que ainda é um objeto pouco explorado pela literatura.

O presente artigo evidenciou, no âmbito de sua investigação, os seguintes desafios na adoção de concessões e diferentes modelos de gestão:

1) A possibilidade de avanço na gestão dos parques por meio das parcerias depende de características da governança estabelecida, tanto em termos regulatórios, com a elaboração de bons contratos, como da capacidade de o governo e a sociedade atuarem sobre esse modelo. Aqui, vale ressaltar que, conforme os depoimentos dos entrevistados, um poder público fortalecido, em termos de gestão e monitoramento, é fundamental para viabilizar um modelo de provisionamento não-estatal da política;

2) A insuficiência do Estado não deve ser utilizada como o principal argumento para a defesa das concessões. Por essa via, que caracteriza o viés neoliberal da proposta, as concessões tendem a gerar uma situação de dependência, comprometendo as funções públicas dos parques. Neste sentido, ao invés de se partir de uma visão dualista e excludente, deve-se pensar num modelo de articulação entre as partes em torno de objetivos comuns. Considerando este contexto, é importante que os setores envolvidos se voltem para defender determinados valores públicos, como a conservação do patrimônio natural e cultural, e a legitimidade do processo por meio da participação efetiva das populações locais na tomada de decisão sobre o modelo de turismo que se deseja nos parques;

3) É preciso fazer com que a responsabilização, em suas múltiplas dimensões, seja a base dos processos de concessão ou parceria dos parques. Nesse sentido, três elementos são peças-chave: a transparência, de modo a aumentar a capacidade de os reguladores e a sociedade controlarem o desempenho de quem provisiona o serviço; a criação de uma comunicação eficaz, que estimule a confiança entre os envolvidos; e a participação social, que fortalece a accountability e aumenta a legitimidade do processo. 0 fortalecimento da responsabilização, ressalte-se, não é uma questão apenas de instrumentos regulatórios. Deve-se, acima de tudo, realçar esses valores públicos que guiam os processos de parceria.

Em síntese, a nova governança proposta pela literatura (Torfing, Peters, Pierre \& Sorensen, 2012) envolve a combinação entre desempenho e democratização, e a análise empírica do caso brasileiro indicou uma maior preocupação com a eficiência do que com a transparência e a participação. Esse descompasso pode prejudicar o alcance dos valores públicos que devem orientar a gestão de parques e do patrimônio natural.

O novo modelo de governança em parques públicos brasileiros, caracterizado pela adoção de parcerias, colocou o debate para além da dicotomia entre o público e o privado. 0 estudo realçou as potencialidades dessa proposta: novos instrumentos de gestão e valores públicos de accountability e vinculados à especificidade da política pública em questão - a conservação do patrimônio natural e cultural e o seu usufruto pelo público - influenciam o paradigma tradicional de provisão de serviços para a sociedade. Porém, essa mudança depende também de um governo estruturado para regular os entes privados e promover a compreensão sobre o impacto das concessões para a sociedade e a conservação da natureza.

\section{AGRADECIMENTOS}

Á Fundação Getulio Vargas / Escola de Administração de Empresas de São Paulo (FGV/EAESP). 


\section{REFERENCIAS}

Balmford A; Green JMH; Anderson M; Beresford J; Huang C; Naidoo R. (2015) Walk on the Wild Side: Estimating the Global Magnitude of Visits to Protected Areas. PLoS Biol 13(2): e1002074. doi: http://dx.doi.org/10.1371/journal.pbio.1002074.

Botelho E. S. \& Rodrigues, C. G. O. (2016). Inserção das iniciativas de base comunitária no desenvolvimento do turismo em parques nacionais. Caderno Virtual de Turismo. Rio de Janeiro, 16(2), p. 280-295, ago.

Braga de Souza, O. (2017) ISA e organizações pedem a Janot ação contra a Lei de concessão de parques. Disponivel em: https://www.socioambiental.org/pt-br/noticias-socioambientais/isa-e-organizacoes-pedema-janot-acao-contra-lei-de-concessao-de-parques. Acesso em: outubro de 2018.

Braga, A. S. (2013). Parques nacionais: participação privada na viabilização do uso público. Curitiba: Edições CRV.

Brasil (1995) Lei $n^{\circ} 8.987$, de 13 de fevereiro de 1995. Dispõe sobre o regime de concessão e permissão da prestação de serviços públicos previsto no art. 175 da Constituição Federal, e dá outras providências.

Brasil. (2000) Lei $n^{\circ}$ 9.985, de 18 de julho de 2000 e Decreto 4.340, de 22 de agosto de 2002. 3.ed. Brasília: Ministério do Meio Ambiente / Secretaria de Biodiversidade e Florestas, 52p.

Brasil (2004) Lei n 11.079, de 30 de dezembro de 2004. Institui normas gerais para licitação e contratação de parceria público-privada no âmbito da administração pública.

Brasil (2014) Lei $n^{\circ}$ 13.019, de 31 de julho de 2014. Estabelece o regime jurídico das parcerias entre a administração pública e as organizações da sociedade civil, em regime de mútua cooperação.

Bresser Pereira, L. C. (1998). Reforma do Estado para a cidadania: a reforma gerencial brasileira na perspectiva internacional. São Paulo: Ed. 34; Brasília: ENAP.

Buckley, R. (2012). Tourism, conservation and the Aichi targets. Parks The International Journal of Protected Areas and Conservation, 18(2), p. 12-19

Conselho Latinoamericano de Administração Pública - CLAD. (2016). In: Bresser-Pereira, L. C. Grau, C. N. Responsabilização na administração pública. São Paulo: CLAD/Fundap.

Dinica, V. (2017). Tourism concessions in National Parks: neo-liberal governance experiments for a Conservation Economy in New Zealand. Journal of Sustainable Tourism, 25 (12), p. 1811-1829, DOI: http://dx.doi.org/10.1080/09669582.2015.1115512.

Duarte, R. (2002). Pesquisa qualitativa: reflexões sobre o trabalho de campo. Cadernos de Pesquisa, 115, p. 139-154. Mar.

Eagles, P. (2009). Governance of recreation and tourism partnerships in parks and protected areas. Journal of Sustainable Tourism, 17(2), p. 231-248.

Instituto Chico Mendes de Conservação da Biodiversidade. (2018). Parques do Brasil: visitar é proteger! Estratégia de implementação da visitação em unidades de conservação federais: prioridades de execução 2018-2020. Coordenação Geral de Uso Público e Negócios. Brasília. Disponível em: www.icmbio.gov.br. Acesso em julho de 2018.

Matheus, F. S. \& Raimundo, S. (2017). O resultado das políticas públicas de ecoturismo em unidades de conservação no Brasil e no Canadá. Revista Brasileira de Pesquisa em Turismo, 11(3), p. 454-479 . DOI: http://dx.doi.org/10.7784/rbtur.v11i3.1336

McCool, S. \& Spenceley, A. (2014) Tourism and protected areas: a growing nexus of challenge and opportunity. Koedoe, 56 (2), Art.\#1221, 2 p. http://dx.doi.org/10.4102/koedoe.v56i2.1221.

Ministério do Meio Ambiente. (2006). Diretrizes para visitação em unidades de conservação. Secretaria de Biodiversidade e Florestas. Departamento de Áreas Protegidas. Brasília (DF). 61p.

Moore, S.A \& Weiler, B. (2009). Tourism-protected area partnerships: stoking the fires of innovation. Journal of Sustainable Tourism, 17(2), p. 129-132, DOI: http://dx.doi.org/10.1080/09669580802582506.

Reynaers, A. M. (2013). Public Values in Public-Private Partnerships. Public Administration Review, 74(1), p. 41-50. The American Society for Public Administration. DOI: http://dx.doi.org/10.1111/puar.12137.

Reynaers, A. M. \& Grimmelikhuijsen, S. (2015). Transparency in Public-private partnerships: not so bad after all. Public Administration Review. DOI: http://dx.doi.org/10.1111/padm 12142. 
Rocktaeschel, B. M. M. M. (2006). Terceirização em áreas protegidas: estímulo ao ecoturismo no Brasil. São Paulo: Editora SENAC.

Rodrigues, C. G. O.; Godoy, L. R. C. (2013). Atuação pública e privada na gestão de unidades de conservação: aspectos socioeconômicos da prestação de serviços de apoio à visitação em parques nacionais. Desenvolvimento e Meio Ambiente, v.28, 75-88.

Rodrigues, C. G. O.; Irving, M. A. (2015). Os significados de "público" e o compromisso de inclusão social no acesso aos serviços em apoio ao turismo em parques nacionais. In: Irving, M. A.; Rodrigues, C. G. O. R.; Rabinovici, A.; Costa, H. A. (Orgs.). Turismo, Áreas Protegidas e Inclusão Social: diálogos entre saberes e fazeres. 1. ed. Folio Digital: Letra e Imagem. 131-143.

Secretariat of the Convention on Biological Diversity (2015). Tourism supporting biodiversity: a manual on applying the Convention on Biological Diversity Guidelines on Biodiversity and Tourism Development. Montreal, 56p.

Thompson, A; Massyn, P.J; Pastorelli, J. (2014). Tourism concessions in protected natural areas: guidelines for managers. United Nations Development Programme.

Torfing, J.; Peters, G.; Pierre, J.; Sorensen, E. (2012). Interactive Governance: advancing the paradigm. Oxford University Press. 280p.

Wyman, M; Barborak, J.R.; Inamdar, N.; Stein, T. 2011. Best Practices for Tourism Concessions in Protected Areas: A Review of the Field. Forests. 2, 913-928. doi: http://dx.doi.org/10.3390/f2040913.

\section{Informações sobre os autores}

\section{Camila Gonçalves de Oliveira Rodrigues}

Doutora em Política e Gestão Ambiental. Professora Associada da Universidade Federal Rural do Rio de Janeiro.

Concepção da pesquisa, revisão da literatura, coleta de dados, discussão dos resultados.

ORCID: http://0000-0001-7076-790X.

Email: camila.rodrigues.ufrrj@gmail.com

\section{Fernando Luiz Abrucio}

Doutor em Ciência Política. Professor do Programa de Mestrado e Doutorado em Administração Pública e Governo FGV-Eaesp.

Concepção da pesquisa, revisão da literatura, discussão dos resultados.

ORCID: http://0000-0002-3883-9915.

Email: fernando.abrucio@fgv.br 